\title{
JOHN LOCKE: UM LIBERAL E SUAS CONTRIBUIÇÕES PARA O PENSAMENTO EDUCACIONAL DE SUA ÉPOCA
}

\author{
Lucy Gabrielli Bonifácio da Silva ${ }^{1}$
}

\begin{abstract}
RESUMO: O presente texto tem por objetivo construir um diálogo entre o pensamento liberal do autor inglês John Locke (1632-1704) e suas contribuições para a concepção educacional da época. Consensualmente citado como "pai do liberalismo", Locke sagrou-se como estudioso de diversos campos do conhecimento humano, como o político, o social e o educacional. Para além de um pensador, participou ativamente dos conflitos políticos de seu país, concedendo sustentação teórico-filosófica para a formação de um Estado liberal, produzindo obras que versam, numa interpretação sucinta, sobre o entendimento humano, os direitos dos homens e sua relação com o Estado, e ainda sobre a educação do homem como pressuposto para alcançar a razão e a emancipação para a liberdade. Dessa forma, à luz das ideias de Locke, ressaltou-se a inovação de seu pensamento educacional frente ao contexto histórico da época, associando referências de sua obra "Alguns pensamentos sobre a educação" (1693) com os ideais liberais defendidos pelo autor.
\end{abstract}

Palavras-chave: John Locke. Pensamento educacional. Liberalismo.

\section{JOHN LOCKE: A LIBERAL AND HIS CONTRIBUTIONS TO THE EDUCATIONAL THINKING OF HIS TIME}

\begin{abstract}
This article's purpose is to contribute to the discussion about the liberal thought of the English author John Locke (1632-1704) and his contributions to the educational conceptions of the time. Usually known as the "Father of Liberalism", Locke has established himself as a scholar in several fields of human knowledge, such as the political, the social and the educational. Not only a thinker, he actively participated in the political conflicts of his country, providing theoretical and philosophical support to the conception of a liberal State, by producing works that concisely deal with human understanding, human rights and their relationship with the State; and also, on the education of people as a prerequisite to achieve reason and emancipation for freedom. Thus, in the light of Locke's ideas, we intend to emphasize the focus on the innovation of his
\end{abstract}

\footnotetext{
${ }^{1}$ Doutoranda em Educação na Faculdade de Educação da USP - FEUSP, área de concentração Educação e Ciências Sociais: desigualdades e diferenças. Mestre em História Social pela Pontifícia Universidade Católica de São Paulo (2010), com Bolsa CAPES. Professora de Ensino Fundamental II e Médio na Prefeitura de São Paulo. São Paulo/SP - Brasil. E-mail: lucy.gabrielli@usp.br
} 
educational thinking in the historical context of the time, associating references from his work "Some thoughts on education" (1693) with the liberal ideals defended by the author.

Keyworks: John Locke. Educational thinking. Liberalism.

\section{JOHN LOCKE: UN LIBERAL Y SUS CONTRIBUCIONES PARA EL PENSAMIENTO EDUCATIVO DE SU TIEMPO}

RESUMEN: Este texto tiene por objetivo construir un diálogo entre el pensamiento liberal del autor inglés John Locke (1632-1704) y sus contribuciones a la concepción educativa de la época. Consensualmente considerado el "Padre del Liberalismo", Locke se ha establecido como un erudito en varios campos del conocimiento humano, como el político, el social y el educativo. Además de ser un pensador, participó activamente en los conflictos políticos de su país, proporcionando apoyo teórico y filosófico para la formación de un Estado liberal, produciendo obras que tratan, en una interpretación sucinta, sobre la comprensión humana, los derechos de los hombres y su relación con el Estado, y también sobre la educación del hombre como requisito previo para llegar a la razón y la emancipación para la libertad. Por lo tanto, a la luz de las ideas de Locke, se pretende enfatizar la innovación de su pensamiento educativo en el contexto histórico de la época, asociando referencias de su obra, "Algunos pensamientos sobre la educación" (1693), con los ideales liberales defendidos por el autor.

Palabras clave: John Locke. Pensamiento educativo. Liberalismo.

\section{Introdução}

Com a pretensão de estabelecer uma relação entre o pensamento liberal do autor inglês John Locke (1632-1704) e suas contribuições para o cenário educacional da época, idealizando a formação de um "novo" homem, cuja educação conduziria à razão e, consequentemente, ao exercício pleno das liberdades, refletiremos sobre suas concepções pedagógicas, especificamente na obra "Alguns pensamentos sobre a educação", relacionando-as às demais ideias liberais expostas nas obras e conceitos desenvolvidos pelo autor.

Ainda que a obra norteadora desta discussão não tenha sido escrita com o intuito de publicação, tendo como base correspondências escritas por Locke ao seu amigo Edward Clarke e esposa, que haviam Ihe solicitado conselhos sobre a educação 
do jovem filho do casal, certamente ela revela os ideais de educação considerados desejáveis pelo filósofo. Assim, configura uma síntese acerca dos elementos indispensáveis para a formação do homem apto ao exercício das atividades econômicas e sociais da aristocracia burguesa, classe em ascensão no contexto histórico inglês em que a obra foi redigida.

Sendo assim, é imprescindível iniciar pela contextualização histórico-social do período em que Locke formulou suas ideias, isso porque nos ajuda a compreender a importância e o impacto das obras desse filósofo sobre o pensamento intelectual, bem como a situar seu ponto de vista acerca do conhecimento humano. Em um cenário caracterizado pelos turbulentos anos da chamada Revolução Gloriosa (1685-1688) e pela consolidação da monarquia parlamentar inglesa ${ }^{2}$, um marco da vitória burguesa sobre o absolutismo, e em meio à efervescência de novas e velhas teorias acerca do Estado, no principal momento de sua produção intelectual, Locke não só contribuiu com reflexões filosóficas como participou ativamente da política do seu país como defensor do liberalismo.

\section{Política e pensamento na época de Locke}

Ainda que seja evidente a importância de retroceder na história para um entendimento mais abrangente, o quanto fazê-lo é uma inquietação só apaziguada com foco no objetivo, atendo-se especificamente às problematizações impostas. Nesse caso, o quanto seria necessário retroceder para demonstrar a influência do pensamento lockeano? Poderíamos atentar para todas as transformações políticas e ideológicas ocorridas na Europa a partir da Reforma Protestante e do absolutismo, o que certamente colaboraria para entender o porquê de pensadores tão díspares no século XVII, e do processo histórico singular ocorrido na Inglaterra.

\footnotetext{
${ }^{2}$ A afirmação se sustenta considerando o início das turbulências políticas inglesas a partir da ascensão ao trono do rei católico Jaime II (1685), culminando com sua deposição em 1688 e início do reinado do protestante Guilherme de Orange (1650-1702), cuja consolidação do poder se deu apenas em 1690, na Batalha de Boyne, na qual as forças de Jaime II foram derrotadas; o legado de transição entre o absolutismo Stuart e a monarquia parlamentar do governo de Guilherme de Orange; e ainda considerando que as principais obras de John Locke surgiram entre os anos de 1689-1693 (Cartas sobre a tolerância, Dois Tratados sobre o governo, Ensaio acerca do entendimento humano e Alguns pensamentos sobre a educação).
} 
Contudo, primando pela objetividade, iniciaremos pelo absolutismo inglês da transição da dinastia Tudor para a Stuart, verificando quais pensadores subsidiavam esse modelo político. O início do absolutismo na Inglaterra se deu com a ascensão ao trono de Henrique VII (1485), seu sucessor Henrique VIII (1509-1547) ampliou o poder real ao romper com a Igreja Católica e submeter a recém-criada Igreja Anglicana à autoridade real - Ato de Supremacia, 1534. Embora esse seja um marco da reforma religiosa inglesa, cabe considerar que o pensamento protestante, difundido anos antes com Lutero (1483-1546) e Calvino (1509-1564), já ecoava na Europa, fazendo-se ouvir inclusive na Inglaterra, cuja doutrina calvinista difundiu-se, originando os presbiterianos na Escócia e os puritanos na Inglaterra.

Mesmo levando em conta que a efervescência religiosa desencadeou uma série de fatores por toda a Europa, caracterizando o rompimento de alguns países com o cristianismo católico e suas estruturas consolidadas, o caso inglês se diferenciava não por adotar uma outra religião, mas pela criação de uma nova, a partir do rei, cuja base não era teológica - visto que a doutrina anglicana possui uma liturgia mais próxima do catolicismo do que do protestantismo -, mas sobretudo política.

Após a morte de Henrique VIII, a Inglaterra passou por momentos de conflito com seus sucessores, motivados por questões religiosas, como a tentativa de Maria I de restabelecer o catolicismo. Somente durante o reinado de Elizabeth I (1557-1603) o absolutismo monárquico inglês atingiria seu ápice. Conhecida pela habilidade política em manobrar o Parlamento, seu governo foi apelidado de absolutismo disfarçado, e a Inglaterra obteve desenvolvimento econômico, artístico, cultural e uma relativa paz nos conflitos religiosos.

Como Elizabeth I não deixou herdeiros diretos, seu parente mais próximo, Jaime I, assumiu o governo (1603-1625), iniciando a dinastia Stuart. O rei, procurando fortalecer seu poder, minimizou as influências do Parlamento em suas ações e tentou reforçar o anglicanismo através da perseguição aos católicos e puritanos. Seu sucessor, Carlos I (1625-1645), com as mesmas pretensões do pai, continuou a ignorar as leis que previam a consulta ao Parlamento, o dissolveu e convocou diversas vezes, gerando protestos, que culminaram numa guerra civil: de um lado, o exército real formado pela alta nobreza e alta cúpula da Igreja Anglicana, de outro, os gentry, exército parlamentar de camponeses e burgueses, na maioria puritanos. Esse conflito, denominado Revolução Puritana, acabou com a vitória dos parlamentares sob o 
comando de Oliver Crowell (1645) e a prisão, julgamento e decapitação de Carlos I (1649).

Crowell governou com toda a autoridade. Com o apoio do exército, dissolveu o Parlamento, sufocou rebeliões na Escócia e na Irlanda, assinou tratados comerciais favorecendo a burguesia comercial inglesa (Atos de Navegação, 1651) e se autoproclamou "Lorde Protetor" da Inglaterra. Após sua morte, em 1658, o filho Ricardo assumiu o poder, mas, muito frágil politicamente e temendo uma nova guerra civil pelo governo do país, o Parlamento engendrou a Restauração Monárquica (1660), sob a condição da submissão do rei ao Parlamento. Assim, embora os acontecimentos políticos citados demonstrem uma crescente insatisfação com a concentração do poder real, no caso inglês iniciada com a dinastia Stuart e potencializada pela falta de tolerância religiosa, é importante ressaltar que o absolutismo se sustentava politicamente, entre outros fatores, apoiado em teorias filosóficas que defendiam sua importância e necessidade.

De forma sucinta, podemos citar as teorias de Jacques Bossuet (1627-1704), bispo e teólogo francês, que afirmava que o poder do rei era concedido por Deus, sendo assim, sua autoridade seria sagrada e ilimitada (Teoria do Direito Divino); e Thomas Hobbes (1588-1679), filósofo inglês, desenvolveu seu pensamento com bases racionais, e não religiosas, defendendo que para se compreender a sociedade atual e ele é contemporâneo das Revoluções Inglesas - é necessário entender o homem em seu estado de natureza, concluindo que todos os homens são iguais, mas naturalmente perversos e vivem em estado de guerra, por isso, para viver em sociedade, eles celebram um contrato social, abrindo mão de parte de sua liberdade original em prol do respeito mútuo.

Hobbes ainda é considerado um precursor do rompimento com o pensamento aristotélico, ao refutá-lo sobre a natureza social do homem, uma vez que, segundo sua teoria, a sociedade é um corpo político artificial criado por um contrato entre os homens. Dessa forma, ao aceitar o contrato social, os homens transferem sua liberdade de autogoverno para o soberano, Estado, que pode estar representado no indivíduo (monarca) ou numa assembleia (parlamento), e lhe conferem poder absoluto para conduzir o povo à paz e à segurança, não devendo, portanto, ter seu poder contestado, pois isso romperia o contrato social, levando a desordem. 
Podemos depreender sobre Bossuet (1627-1704) e Hobbes (1588-1679) que, mesmo utilizando fundamentos teóricos distintos, ambos defendiam a autoridade absoluta do Estado. Para o primeiro, como um fato natural, haja vista a origem divina da relação social; para o segundo, um poder conferido pelo povo, para o bem-estar do povo, que incumbe o Estado de total autoridade para governá-lo.

Cabe considerar que o processo de mudança na interpretação das vivências humanas, destituindo-as cada vez mais do caráter religioso, é resultado de reflexões iniciadas durante o Renascimento Cultural, que, num movimento progressivo, ao custo de diferentes autores, tentariam responder às novas demandas criadas pelas transformações ocorridas nas sociedades europeias nos séculos XVII e XVIII, que exigiram uma correspondente alteração na forma de perceber o mundo, iniciando a chamada Revolução Intelectual que culminou no lluminismo.

John Locke (1632-1704), nascido durante a Revolução Puritana e filho de um defensor do Parlamento, também foi influenciado pelo contexto político de seu país. Após a Restauração Monárquica (1660), ascendeu ao trono Carlos II, que tentou restabelecer o catolicismo na Inglaterra, ação que obteve resposta imediata do Parlamento, que instituiu o habeas corpus, para evitar prisões arbitrárias, e a proibição de nomear católicos para altos cargos governamentais. Após sua morte, em 1685, assumiu o trono Jaime II, declaradamente católico e com pretensões absolutistas. Receoso de um novo conflito, o Parlamento acordou com Guilherme de Orange, holandês casado com uma das filhas protestantes de Jaime II, sua coroação como rei da Inglaterra. Jaime II não teve como oferecer resistência, foi deposto e exilado na França. Guilherme de Orange e sua esposa Maria, então sob o título de Guilherme III e Maria II, foram coroados como soberanos (1688), fato histórico conhecido como Revolução Gloriosa.

Locke teve um papel muito importante durante esse período. Em 1687 tomou parte da conspiração para a deposição de Jaime II, e após a ascensão de Guilherme III escreveu a obra Dois tratados sobre o governo civil (1689), na qual, no Primeiro Tratado, refuta as ideias de Robert Filmer (1588-1653), autor de O Patriarca, que afirmava que o povo não era livre para escolher sua forma de governo, pois os monarcas possuíam um poder inato. No Segundo Tratado, Locke propõe que o estado de sociedade e, consequentemente, o poder político nascem do contrato social (LOCKE, 1978). 
Ainda que Hobbes também tenha defendido a ideia de um contrato social, os pensamentos dos dois divergem na concepção do estado natural. No pensamento lockeano, o homem em estado natural vivia em perfeita liberdade e igualdade, conduzido pela razão,

[...] contudo, estaria exposto a certos inconvenientes. O principal seria a possível inclinação no sentido de beneficiar-se a si próprio ou a seus amigos. Como consequência, o gozo da propriedade e a conservação da liberdade e da igualdade ficariam seriamente ameaçados (LOCKE, 1978, p. 21).

Nesse sentido, para Locke, o pacto social não representa renúncia aos direitos naturais do homem, e sim um esforço coletivo para a execução das leis naturais, cujo objetivo seria a preservação da vida, da liberdade e da propriedade. Ainda se diferenciando de Hobbes, Locke defende a soberania do povo, que, segundo ele, pode instalar a forma de governo que julgue conveniente, bem como revogá-la, legitimando em seus escritos o direito à resistência e insurreição.

As ideias de Locke são tão significativas que, um século depois, foram uma das bases teóricas do movimento de independência das Treze Colônias inglesas na América (MERQUIOR, 1991).

\section{O caráter liberal do pensamento de Locke}

Dadas as circunstâncias em que Locke se constituiu como intelectual, passemos a refletir sobre sua principal alcunha, a de "pai do liberalismo". Afinal, o que emerge da obra lockeana que lhe concede esse lugar na história? Primeiramente, cabe a delimitação do significado de liberalismo e quais suas origens:

Por consenso histórico, o liberalismo (a coisa senão o nome) surgiu na Inglaterra na luta política que culminou na Revolução Gloriosa de 1688 contra Jaime II. Os objetivos dos vencedores da Revolução Gloriosa era tolerância religiosa e governo constitucional. Ambos tornaram-se pilares do sistema liberal, espalhando-se com o tempo pelo Ocidente. No século que medeia entre a Revolução Gloriosa e a Grande Revolução Francesa de 17891799, o liberalismo - ou melhor, protoliberalismo - era constantemente associado com o "sistema inglês" - ou seja, uma forma de governo fundada em poder monárquico limitado e num bom grau de liberdade civil e religiosa. $\mathrm{Na}$ Inglaterra, embora o acesso ao poder fosse controlado por uma oligarquia, fora refreado o poder arbitrário, e havia mais liberdade em geral do que em qualquer outra parte da Europa (MERQUIOR, 1991, p. 16). 
Com essas primeiras afirmações, podemos compreender o lugar de destaque de Locke na concepção do que se entende por liberalismo em sua origem, ou protoliberalismo, como denomina Merquior. Se as consequências políticas da Revolução Gloriosa fundamentam o primeiro modelo de governo liberal, é aceitável que seu principal teórico seja considerado seu criador. Isso porque, como salientado anteriormente, Locke se distância de seus antecessores ingleses, Hobbes e Filmer, ao afirmar que o poder político brota inteiramente do consentimento, como Merquior (1991, p. 68-69) explica:

\footnotetext{
Os Dois Tratados desenvolveram, a um tempo, uma teoria do consentimento e uma teoria da confiança. A teoria do consentimento respondia pela legitimidade do governo (e comparava o absolutismo à guerra social). A teoria da confiança mostrava como os governantes e súditos deviam compreender o seu relacionamento recíproco. Nenhuma das duas teorias jamais foi abandonada pelas tradições liberais subsequentes, apesar de sua diversidade. [...] enquanto os pensadores antigos e medievais escreveram com um objetivo platônico de idealizar uma boa sociedade, e enquanto Hobbes se preocupava com a conquista da ordem, a filosofia política de Locke foi a primeira altamente influente que objetivou o estabelecimento das condições de liberdade.
}

Considerando essa preocupação com o "estabelecimento das condições de liberdade", caminhamos para abordar o pensamento de Locke acerca de como se preparar para o exercício da liberdade. Segundo Sanchez (2008?), a obra Ensaio sobre o entendimento humano (1690) "é o ponto de partida para entender o pensamento filosófico, social, político e educacional de John Locke" (LOCKE, 1978, p. 2). Essa obra, dedicada a refutar o conceito de inatismo, justifica que "não há nada passível de receber de todos os homens um assentimento universal" (LOCKE, 1978, p. 145).

Ao investigar o entendimento humano, afirmando que é justamente o "entendimento que situa o homem acima dos outros seres sensíveis, e dá-lhe toda a vantagem e domínio que tem sobre eles" (LOCKE, 1978, p. 139), Locke se contrapõe à teoria do inatismo, defendida por Descarte (1596-1650) e Ralph Cudworth (16161688), através do empirismo, ou seja, a "razão, a verdade, as ideias racionais são adquiridas por nós pela experiência" (CHAUI, 2013, p. 86). Locke, assim como outros estudiosos, constituiu um teórico empirista, ao afirmar que a fonte de todo o conhecimento são a experiência sensível e a reflexão. 
Todas as ideias derivam da sensação ou reflexão. Suponhamos, pois, que a mente é, como dissemos, um papel branco, desprovido de todos os caracteres, sem quaisquer ideias; como ela será suprida? De onde lhe provem este vasto estoque, que a ativa e que a ilimitada fantasia do homem pintou nela com uma variedade quase infinita? De onde apreende todos os materiais da razão e do conhecimento? A isso respondo, numa palavra, da experiência. Todo o nosso conhecimento está nela fundado, e dela deriva fundamentalmente o próprio conhecimento. Empregada tanto nos objetos sensíveis externos, como nas operações internas de nossas mentes, que são por nós mesmos percebidas e refletidas, nossa observação supre nossos entendimentos com todos os materiais do pensamento. Dessas duas fontes de conhecimento jorram todas as nossas ideias, ou as que possivelmente teremos (LOCKE, 1978, p. 159).

Segundo ele, nascemos sem nenhum tipo de ideia, e os conhecimentos se formam de acordo com nossas experiências externas e combinações internas. A filósofa Chauí (2013, p. 143) sintetiza esse processo com as seguintes palavras:

[...] por meio das sensações, recebemos as impressões das coisas externas; essas impressões formam o que Locke chama ideias simples. Por sua vez, nas percepções, essas impressões ou ideias simples se associam por semelhanças e diferenças, formando ideias complexas ou compostas.

Daí em diante, a associação e combinação de ideias se tornam mais complexas na razão, originando as ideias abstratas.

Nesse ponto, pode-se dizer que a crítica ao inatismo permeia também as teorias políticas de Locke, pois, da mesma forma que não existem ideias inatas nos seres humanos, não existe poder que possa ser considerado inato e de origem divina, ou seja, descaracterizando-se mais uma vez as argumentações dos teóricos do absolutismo. Se o homem nasce como uma "tábula rasa" que depende de experiências para a formação de ideias, nada mais natural que Locke ter se dedicado a alguns escritos sobre a educação, afinal, como preencher de forma satisfatória essa "folha em branco"? Ao responder às dúvidas de Sir. Edward Clarke, Locke nos legou os caminhos para uma educação que garantiria a formação de um homem integral, útil e virtuoso.

\section{Locke e suas contribuições para o pensamento educacional}

Decerto não é apenas na obra "Alguns pensamentos sobre a educação" (1693) que as contribuições de Locke podem ser resgatadas. Se refletirmos sobre suas 
principais teses, algumas modestamente abordadas neste trabalho, veremos que de fato seus "pensamentos sobre a educação" são a culminância de toda a sua reflexão acerca do entendimento humano e das relações desse homem em sociedade. Segundo Sanchez (2008?) essa obra consiste em uma síntese das experiências práticas e convicções múltiplas de Locke, advindas de seu conhecimento médico, sua experiência como tutor, suas convicções políticas e religiosas e uma concepção de destino do homem.

Vale ressaltar que Locke apresenta a educação como um caminho para a prosperidade da nação: "A boa educação dos filhos é de tal forma um dever e a missão dos pais, e o bem-estar e a prosperidade das nações depende tanto dela, que gostaria de levar essa convicção ao coração de todos" (LOCKE, 2012, p. 54). Ou seja, educar as crianças não é apenas um ato de ilustração, de verniz social, mas de importância, ao ponto de dela depender a prosperidade do país.

Assim, a obra se inicia com considerações sobre a saúde do corpo, cuidados de higiene e vestimentas adequadas, destacando a necessidade de cuidar do corpo tanto quanto do espírito desde cedo, pois o corpo deve ser preparado para executar todas as obras do espírito. Em suas palavras,

\footnotetext{
"Um espírito são em um corpo são" tal é a breve, mas completa definição da felicidade nesse mundo. $O$ homem que possui essas duas vantagens nada mais tem a desejar. Aquele que falta uma ou outra não teria nada a lucrar com outro bem. A felicidade ou infelicidade do homem é em grande parte a sua obra. Aquele cujo espírito não sabe como se dirigir com sabedoria não saberá jamais o caminho direito; e aquele cujo corpo é fraco e débil, será incapaz de caminhar (LOCKE, 1966, p. 27).
}

Diante das diferentes instruções que se seguem pelo texto, não de forma linear, mas num formato de reafirmação de elementos fundamentais de sua proposta, e na impossibilidade de abordar todas, vamos nos ater a quatro delas: a razão, a disciplina, a vergonha e a virtude. A razão é o fio condutor do pensamento educacional lockeano, uma vez que é por meio da educação que o homem ascenderá à razão e, a partir daí, exercerá seu direito natural de liberdade, tornando-se capaz de distinguir e fazer escolhas racionais na sociedade em que vive. Também é na qualidade da educação recebida que Locke identifica que se moldam as diferenças entre os homens: "[...] as diferenças entre os costumes e as aptidões dos homens provêm da sua educação" 
(LOCKE, 2012, p. 90). Por isso, adverte que a criança deve recebê-la desde muito cedo, caso contrário, seus maus hábitos não poderão ser corrigidos - quanto mais velhos, mais seus defeitos sobressairão, e crianças más se tornam adultos maus.

Nesse sentido, as afirmações de Locke acerca da precocidade do início da educação corroboram a teoria da "tábula rasa": uma vez que nascemos sem nenhuma ideia, necessitando da experiência para adquiri-las, é essencial que isso se faça o quanto antes, já que, por meio de experiências controladas, as crianças poderão adquirir as aptidões mais adequadas. A aquisição da razão se fundamenta ainda na superação dos próprios desejos e inclinações, através da virtude e do mérito, para "seguir unicamente aquilo que a razão lhe dita como o melhor" (LOCKE, 2012, p. 91).

Mesmo pregando a disciplina e o autocontrole, Locke se mostra atento aos diferentes gostos e desejos de cada idade, o que, segundo ele, não configura um problema, a questão central é não saber submetê-los às regras e decisões da razão. $E$ reconhece na infância momento próprio para o aprendizado, que pode ser frutífero, resultando no homem virtuoso, ou pode representar o desvio da virtude, quando os pais ou seus mestres o corrompem com falsos valores, como a vaidade, a inveja, a mentira, a gula, ou seja, os excessos e vícios (LOCKE, 2012).

A superação dos desejos só é possível através da razão, mas para alcançá-la a criança deve seguir na virtude e na honra. Assim, Locke propõe que a disciplina é fundamental, não a indica como um ato de violência, algo a ser conquistado por meio de castigos físicos ou humilhantes, em vez disso, sugere atitudes disciplinadoras através da submissão das vontades. Ao reconhecer as especificidades de cada faixa etária e suas capacidades de entendimento, os pais ou mestres devem fazê-las entender os comandos que lhes são dados e a razão dessas ordens. Não que se deva tratar as crianças como sábias, ou miniadultos, elas devem ser tratadas com certa indulgência, com ternura, devem brincar, mas é dever de seus guardiões negar-lhes o que não for conveniente à sua formação e fazê-las compreender isso, de modo que sejam submissas ao poder e domínio daqueles que as guardam (LOCKE, 2012). Sua proposta disciplinadora considera que, quando menores, as crianças devem ser disciplinadas com severidade para obter submissão, quando mais velhas, os pais devem admiti-las com mais intimamente e familiaridade. 
Creio que todos julgarão razoável que os filhos, quando são pequenos, devem ver os pais como seus senhores, como seus governantes absolutos e que, como os temem, quando chegarem à idade adulta verão neles seus melhores amigos, os únicos amigos seguros, e que, como tal, os amem e respeitem (LOCKE, 2012, p. 102).

Então, embora Locke proponha uma educação disciplinadora, pode-se dizer que, quando bem-educadas desde cedo, conforme crescem, as crianças deixam de necessitar de reprimendas e castigos, pois o objetivo não é formar homens cujo domínio sobre suas inclinações seja forçado ou se dê pelo conformismo, mas adultos incutidos dos verdadeiros princípios de virtude e prudência, de modo que sua prática seja natural ao espírito. Assim, o autor aponta o segredo da educação, que consiste em conservar nas crianças o espírito fácil, ativo e vivo, afastando-as das coisas que as atraem e inclinando-as para ações que Ihes sejam desagradáveis. E aqueles que não alcançarem esse equilíbrio entre a disciplina e o fortalecimento do espírito podem acabar incorrendo em outros caminhos que não asseguram o sucesso desejado (Figura 1) (LOCKE, 2012).

Figura 1- Esquema de consequências de uma disciplina muito rigorosa.

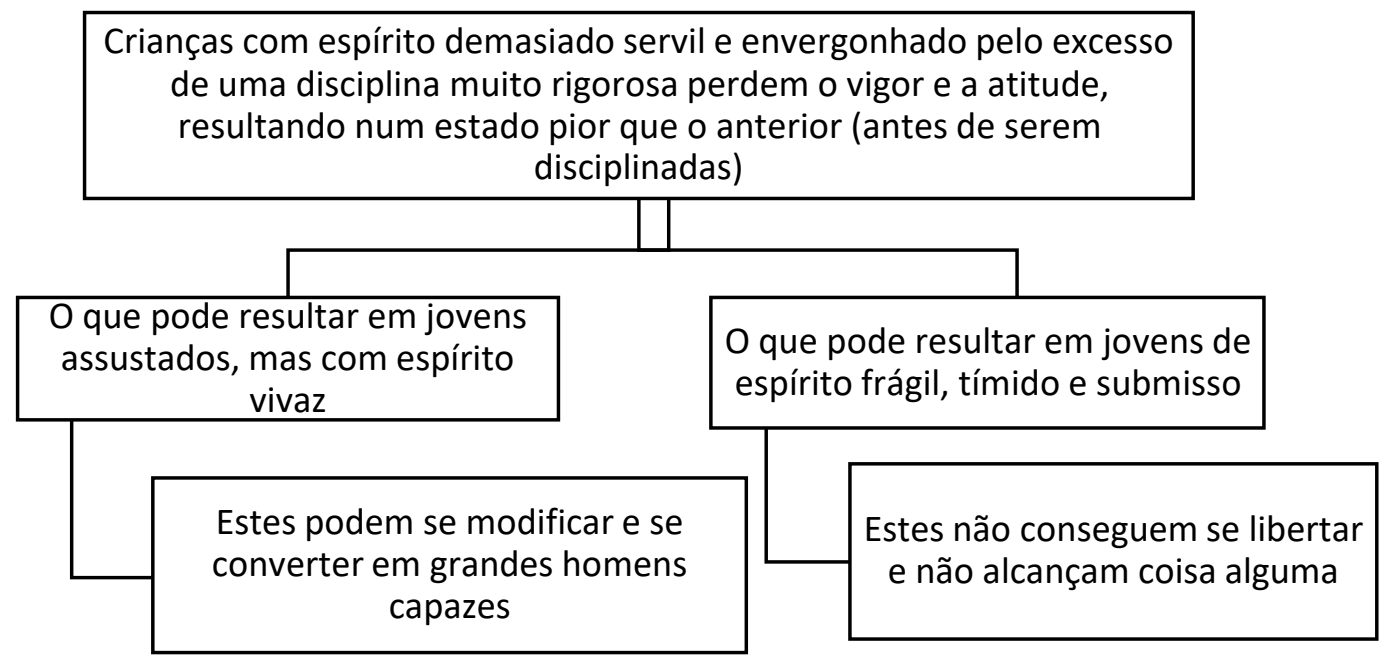

Fonte: Elaborado pela autora fundamentando-se em Locke (2012).

Para fazer valer a disciplina, respeitando os limites entre a severidade e o fortalecimento do espírito, os castigos físicos são desaconselhados, como já dito, pois 
as crianças passam a obedecer por medo, mas, assim que tiverem oportunidade, seguirão suas inclinações naturais. Locke indica um método que consiste em conseguir inspirar nos filhos o amor e o sentimento de honra e, em contrapartida, o medo da vergonha e da desonra, para só assim conseguir estabelecer os verdadeiros princípios que não cessarão.

Dessa forma, as crianças devem ser elogiadas, acarinhadas quando realizam qualquer coisa boa, pois elas sentem prazer por serem estimadas e apreciadas por aqueles de que dependem, mas, quando fizerem algo mau, devem sentir diferença no tratamento, demonstrando claramente desagrado e fazendo-as se envergonhar de seus erros. Com o tempo, compreenderão que existem dois estados diferentes das coisas: agradáveis, reservadas unicamente para aqueles que mantêm boa reputação; e desagradáveis, associadas a vergonha das más ações (LOCKE, 2012).

Seria então o medo da vergonha o regulador de comportamento mais eficiente. As crianças devem ser estimuladas a se preocupar com a sua reputação, isto é, a forma como são reconhecidas em suas atitudes determina o tratamento que será recebido. Logo, para Locke, a reputação é o guia adequado e o maior estímulo das crianças até que se desenvolvam o suficiente para encontrar a retidão através da própria razão. $A$ virtude, símbolo da boa educação, é definida como o conhecimento que o homem tem do seu dever, o prazer de obedecer ao Criador e seguir suas orientações (LOCKE, 2012). Para incentivar a boa reputação, a criança deve ser elogiada na frente de todos sempre que mereça, em contrapartida, as reprimendas devem ser realizadas em âmbito privado, com seriedade, mas de forma desapaixonada, demonstrando autocontrole.

Outro ponto que não deve ser esquecido é o valor dado à figura do preceptor, ressaltando que ele deve ser respeitado por todos da família, não apenas pela criança, deve dar o exemplo, precisa ser bem remunerado e deve ter caráter sóbrio, de boa instrução e educação.

O bom preceptor ensinará ao seu discípulo a adivinhar as intenções dos homens com quem se vai relacionar, proteger-se dos seus propósitos, sem ser demasiado desconfiado ou demasiado incrédulo; mas como os homens têm uma propensão natural para esse último excesso [...] deve habituá-lo, dentro do possível, a julgar de forma sã os homens, de acordo com os sinais que melhor servem para descobrir o seu verdadeiro caráter (LOCKE, 2012, p. 178). 
Ao professar a importância do preceptor não só para o preparo dos conhecimentos teóricos, mas para a vida em sociedade, percebe-se que "o aspecto mais vital da educação está na formação de costumes, não necessariamente nos saberes técnicos acumulados. A finalidade essencial da educação é o autodomínio, a capacidade da própria razão de orientar as ações do homem" (ROSSETTO, 2015, p. 99). Mais uma vez nos deparamos com a razão como elemento essencial para a liberdade.

$\mathrm{Na}$ impossibilidade de tratar de todos os aspectos contidos na obra, deixemos ainda alguns indícios de suas contribuições, como: a importância das regras; do reconhecimento das aptidões e da natureza das crianças para que sejam incentivadas; a necessidade de ensinar boas maneiras desde cedo através do exemplo e do convívio; alerta para o convívio danoso das crianças com os empregados mais humildes (LOCKE, 2012). Ademais, Locke responde a uma inquietação comum à época: o que seria melhor para a educação da criança, fazê-la em casa ou em instituições de ensino?

Sobre isso, faz uma observação interessante: a criança ensinada fora de casa teria espírito mais preparado para os desafios, já a educada em casa, quando se apresentar ao mundo, será um ser tímido ou obstinado. Ainda assim, o autor afirma que, até que se encontre uma escola em que o professor tenha tempo para vigiar seus discípulos, e cuja experiência prove que cuida tanto de dar-lhe boa educação quanto de formar seu espírito em virtude, a educação em casa seria a melhor opção. Afinal, quais virtudes podem ser obtidas em uma escola que reúna crianças provenientes de todo gênero de famílias? E alerta que a influência do convívio com os colegas na escola é mais forte do que todas as lições do professor (LOCKE, 2012).

\section{Considerações finais}

Mais que uma referência bibliográfica, "Alguns pensamentos sobre a educação" (1693) descreve o pensamento educacional de Locke, objetivando a formação de um "gentleman". E, sim, a proximidade com sua obra sugere exatamente isso, a formação do homem capaz de lidar com as transformações de sua época, mas não qualquer homem, o aristocrata. Pensar na educação dos futuros líderes de suas comunidades Ihe custou críticas quanto ao caráter utilitarista da educação classista proposta, pois não teria a função de fomentar a igualdade social, como salienta Rossetto (2015). 
Embora seja possível reconhecer a hierarquia social em suas ideias, vista, por exemplo, na forma como encara a influência dos criados, há de se colocar suas ideias em seu tempo para se compreendê-las. Para Locke (2012), temos direitos naturais, todos nós, sem distinção, entre os quais se encontram a liberdade, a igualdade e a propriedade, no entanto, a garantia do gozo desses direitos estaria na razão. Mas que liberdade e igualdade são essas? Parece irônico por se tratar do período histórico em que as metrópoles europeias se beneficiavam da exploração do trabalho escravo em suas colônias.

Mas a liberdade e a igualdade por ele referidas são as conferidas pela razão, ou seja, a capacidade de se autogovernar, de controlar seus impulsos e anseios, tornando o homem senhor de si, em condições de igualdade com aqueles que alcançam as mesmas virtudes. Sua proposta de educação caminha nessa direção, não de subverter a ordem social vigente, mas mudar os homens que nela atuam tornando-os civilizados e morais. Na época em que esses pensamentos foram formulados, refletiam inovação e um caráter liberal, pois defender as liberdades individuais quando boa parte da Europa ainda se cercava de teorias que exaltavam a soberania do Estado emergia como revolucionário.

Também é possível afirmar que a educação por ele proposta estava diretamente ligada às suas teorias políticas desenvolvidas anteriormente, pois Locke reconhece o papel fundamental da formação das novas gerações para a garantia da evolução do Estado.

\footnotetext{
E se a inocência, a sobriedade e a atividade das novas gerações não forem cuidadas e preservadas, será ridículo esperar que os que devem suceder-nos no palco do mundo estejam abundantemente providos dessas qualidades de virtude, de habilidade e de cultura que fizeram até agora a Inglaterra digna de contemplação a nível mundial. Acrescentaria também a coragem a esta lista de qualidades, mas esta foi sempre vista como uma herança natural dos ingleses (LOCKE, 2012, p. 140).
}

Assim, sustenta um ideal de educação que pode ser criticamente chamado de utilitarista, mas aqui é interpretado em seu sentido mais benéfico. Para que serviria todo o conhecimento clássico sem conhecer os meandros do mundo em que se vive, ou para o qual não se pudesse colaborar? Não há desprezo sobre o conhecimento das artes liberais ou das ciências enciclopédicas, mas um alerta para que não sejam as 
únicas preocupações, pois "bem cedo verá que esta singular aptidão [ser um homem bem-educado] Ihe abre mais amplamente o caminho para o êxito, fá-lo-á encontrar mais amigos e levá-lo-á mais longe no mundo do que todas as palavras técnicas [...]" (LOCKE, 2012, p. 177). Um homem bem-preparado deve conhecer o mundo de forma objetiva e sagaz.

Sobre os fragmentos destacados neste trabalho, considera-se que os aspectos que fizeram de Locke um reconhecido liberal foram contemplados, ainda que superficialmente, dada a importância e complexidade das obras - e espera-se que também o pensamento educacional do autor tenha se salientado satisfatoriamente. Ainda que não se esgotem por aqui as possibilidades de interpretação, podem-se perceber resquícios das ideias lockeanas na contemporaneidade, mesmo na educação. $E$, de todos os conselhos que Locke escreveu para o Sr. Clarke, encerremos com aquele que se julga configurar como dos mais significativos e atuais:

[...] há que considerar que hoje não é mais possível (como talvez fosse noutros tempos) manter um jovem na ignorância completa dos vícios; pelo menos não queiram tê-lo fechado toda a vida num quarto e proibi-lo do convívio de toda a sociedade. Quanto mais tempo o deixarem assim de olhos vendados menos capaz será de ver claramente quando for lançado à plena luz do dia, e mais exposto estará a ser uma presa das suas próprias paixões e das paixões dos outros. (LOCKE, 2012, p. 181)

Em outras palavras, é necessária uma educação realista, que não poupe os jovens do entendimento das situações que permeiam o mundo em que vivem, e esse conhecimento deve ser progressivo, expandindo-se à medida que aprimoram suas capacidades - quanto mais protegidos da realidade, menos saberão lidar com os desafios por ela imposta. Quer sejam crianças aristocratas inglesas da idade moderna, criadas em suas vastas propriedades, protegidas contra a corrupção dos vícios, quer sejam crianças de classe média criadas em condomínios fechados, protegidas das diversidades e adversidades, guardadas as devidas proporções, Locke nos ensina que o exercício da liberdade só é possível através do conhecimento, nunca na ignorância.

\section{Referências}

CHAUI, Marilena. Iniciação à filosofia. 2. ed. São Paulo: Ática, 2013. 
LOCKE, John. Carta acerca da tolerância: segundo tratado sobre o governo: ensaio acerca do entendimento humano. 2. ed. São Paulo: Abril Cultural, 1978. (Coleção Os pensadores).

LOCKE, John. Alguns pensamentos sobre a educação. Portugal: Almedina, 2012.

LOCKE, John. Quelques penseeÈs sur lí Èducation. Paris: Vrin, 1966.

MERQUIOR, José Guilherme. O liberalismo antigo e moderno. São Paulo:

Realizações, 1991.

ROSSETTO, Miguel da Silva. Liberdade e disciplina em John Locke: as leis da razão no processo de formação humana. Controvérsia. São Leopoldo, v. 11, n. 2, p. 91-102, maio/ago. 2015. Disponível em:

http://revistas.unisinos.br/index.php/controversia/article/view/10488. Acesso em: 23 out. 2019.

SANCHEZ, Ana Maria Brito. A teoria da educação liberal de Locke. São Paulo: Universidade Presbiteriana Mackenzie, 2008. Disponível em: http://creiproferlao.pbworks.com/w/file/fetch/106483584/A\%20teoria\%20da\%20ed uca\%C3\%A7\%C3\%A3o\%20liberal\%20de\%20John\%20Locke.pdf. Acesso em: 23 out. 2019.

Enviado em: $21 / 07 / 2019$

Aprovado em: 16/04/2020 